\title{
Attention Deficit Hyperactivity Disorder and Disruptive Mood Dysregulation Disorder Treatment with Olanzapine and Methylphenidate: A Case Report
}

Zeynep Vatansever*, Hatice Ünver**, Duygu Karagöz*, Nursu Çakın Memik* and Özlem Yıldız Gündoğdu*

*Kocaeli University, Medical Faculty Child and Adolescent Psychiatry, Umuttepe, Kocaeli, Turkey

\begin{abstract}
Attention deficit hyperactivity disorder (ADHD) is one of the most common disorders in childhood which deficits of inattention, hyperactivity and impulsive behavior. Disruptive mood dysregulation disorder is characterized by severe recurrent temper outbursts that are inconsistent with developmental level and manifest verbally or behaviorally. The disorder can co-exist with ADHD and conduct disorder. In treatment of ADHD most common used pharmacological agent is methylphenidate. Atypical antipsychotics (e.g. risperidone, aripiprazole, olanzapine) can be added to treatment in some cases because of unsatisfactory clinical response and comorbidities such as conduct disorder, pervasive developmental disorders, disruptive mood dysregulation disorder, mental retardation. Olanzapine is one of the Food and Drug Administration approved atypical antipsychotics which antagonizing the dopamine (D1, D2, D4), serotonine (5-HT2A, 5-HT2C, 5-HT6), histamine (H1), alpha1- adrenergic and muscarinic (especially M1) receptors. It is used increasingly for the treatment mood disorders, schizophrenia, conduct disorder and pervasive developmental disorders at child and adolescent psychiatry clinics. Studies pointed that olanzapine causes mostly dry mouth, weith gain, increase apetite, sedation and hyperlipidemia. In this article, we report a 8-year-old male patient treated with olanzapine and OROS methylphenidate who have ADHD, disruptive mood dysregulation disorder and conduct disorder. This issue want to get attention that these two psychopharmacologic agent is usable concominantly ADHD and comorbidities.
\end{abstract}

Keywords: ADHD; Olanzapine; Methylphenidate; Disruptive mood dysregulation disorder

\section{Introduction}

ADHD prevalence rates ranged from $\% 3$ to $\% 7$ in school-aged children [1]. It is known that the disorder is more common boys than girls in both epidemiological and clinical samples [2]. ADHD can co-exist with many diseases. The most important comorbidities are conduct disorder and disruptive mood dysregulation disorder because of the effects on impairing functionality. In the patients with ADHD it is reported that the incidence of conduct disorder is \% 20 to \% 50 and disruptive mood dysregulation disorder is $86.9 \%$ [3].

Disruptive mood dysregulation disorder is characterized by impairing and chronic irritability. The patients respond to frustration with extended temper tantrums, verbal rages, and/or aggression toward people or property. Abnormal mood specifically anger or sadness present at least half of the day on most days and of sufficient severity to be noticeable by people in the child's environment [4].

In treatment of ADHD most common used pharmacological agent is methylphenidate. Atypical antipsychotics can be added to treatment in some cases because of unsatisfactory clinical response and comorbidities [5].

In this case report, we discussed the treatment of a 8-year-oldmale patient with methylphenidate and olanzapine, who has ADHD, disruptive mood dysregulation disorder and conduct disorder.

\section{Case}

The case, who has consulted with the day clinic of Kocaeli University Department of Child and Adolescent Psychiatry, is 8-yearold male and a third grade student. It has been deducted that the case includes some serious problems such as; temper tantrum, hyperactivity, lying, taking things which don't belong to him without permission, and telling he will hurt himself when he's mad. After the consultation with him and his family it has been determined that the symptoms of the case have started when he was attending preschool at the age of 6 and his symptoms have increased when he started first grade at the age of 7 .

He was born by caesarean section in 2105 as the second healthy and unscheduled pregnancy of the mother. He was born in term and normal weight, and there weren't any complications after the labor. His motor and mental developmental stages including toilet training right was normal. The case was hurting his friends and was hyperactive in preschool, he wasn't able to continue in at school during his first year when he was 7, once he glued his friend's school bags to the floor, another time he took the money-box at the school's bookstall without permission in front of everyone and claimed insistently that it was his property. It has also been stated that he displayed hyperactivity at school such as making lots of gestures to make his friends laugh whenever his teacher turned his back in the class room, and he never listened to the lectures and he had also been trying to get out of the class and always talked with his friends. The case tore his eraser to pieces, broke his pencil, ripped his notebook, and when he was been questioned about why he had done it, he hadn't answered. He said that his friend had been teasing his talk and gestured to him so he had beaten him. It has been stated that he had pricked his friends because they had been making him angry and mocking him. It has been stated that upon these complaints the ADHD

*Corresponding author: Unver H, Kocaeli University, Medical Faculty Child and Adolescent Psychiatry, Umuttepe, Kocaeli, Turkey, Tel: +0905447693472; E-mail: drhaticeunver@gmail.com

Received: November 02, 2015; Accepted: November 05, 2015; Published: Novomber 30, 2015

Citation: Vatansever Z, Ünver H, Karagöz D, Memik NÇ, Gündoğdu ÖY (2015) Attention Deficit Hyperactivity Disorder and Disruptive Mood Dysregulation Disorder Treatment with Olanzapine and Methylphenidate: A Case Report. Clin Depress 1: 105. doi:10.4172/ cdp.1000105

Copyright: (c) 2015 Vatansever Z,et al. This is an open-access article distributed under the terms of the Creative Commons Attribution License, which permits unrestricted use, distribution, and reproduction in any medium, provided the original author and source are credited. 
diagnosis had been done by a child and adolescent psychiatrist, and the treatment of $2 \mathrm{mg}$ aripiprazole had been started to use. And one year of utilization, due to the decrease of complaints and the request of the family, his treatment was ended by summer time.

While he was a second grade student, he transferred from private school to a public school because the financial problems of his family but he didn't want to go that school, run away and came home, yet he was returned to school by his parents. Because of these complaints his medical treatment has been readjusted by his psychiatrist as $10 \mathrm{mg}$ aripiprazole and $2 \mathrm{mg}$ risperidone. After this treatment it was stated that his escapes from school have decreased and he has started to listen to the lessons. It has also been pointed out that they hadn't sustained medical treatment during the summer. It has been deducted that the case had changed his school twice and started a new school when he had was at third grade. It has been acknowledged that from the first moments of his attendance to this new school he has been displaying hyperactivity again. Also he has taken money without permission from the pocket of his friend who was sitting near him, and took a tablet from the principal's office. Because of all these behavioral problems, the school management stated that they had not been able to control the case, he had distracted the other students therefore they had fallen behind too, thus it was not appropriate for him to continue this school.

The case has always been a restless, irritable and running child. He also has had dysmnesia; he has forgotten his belongings, homework etc. He has been getting bored quickly and pretending not to have heard the things that he had been told. If he didn't win the games he played he had tempered outbursts, and after that he had started throwing things away and spoke of stabbing himself, cried and yelled, hit around, and it took a while for him to calm himself down. In addition, these situations were more often recently.

His mother is 33 years old, a high school graduate and an accountant. His father is 39 years old, an elementary school graduate and runs his own business, he also has a brother who is 15 years old and a sister who is 5 years old. It has also been stated that his brother and sister too have similar but lighter symptoms which he carries. The mother of the case has a unhappy, spiritless and depressed sight which draws attention. When the mother was questioned about the reason for this, she said that she had been feeling helpless because of the case's hyperactivity and disobedience so she had had a great difficulty. The mother has laid the burden of the case's needs and responsibilities on the father, thus it has been observed that the case accepted his father as a figure of authority.

At the first psychiatric examination of the case, he was assessed as thin and younger looking for his age. And he was also avoiding eye contact, and he showed a lack of concentration and attention, nevertheless his self care was well and his clothes were appropriate for his social-economic situation. It was noted that he has started to talk and was willing to communicate. Also the aggression and lack of anger management seen in his expressed attitudes when there had been something that he didn't want or he had failed in the games. His memory and orientation was normal. Mood was euthymic. His process of thought was ordinary and willingness to play games and the aspects of it were predominant in his thoughts. His intelligence was seen as normal clinically.

Through all these evaluations, it was decided that the case should be followed up on and treated in day clinic Kocaeli University Department of Child and Adolescent Psychiatry because of the reason that it would have be difficult to follow up on ambulatory care, because according to DSM-5 the case has ADHD, disruptive mood dysregulation disorder and conduct disorder. His medical treatment gradually increased 54 mg OROS methylphenidate and $10 \mathrm{mg}$ olanzapine has been used. Right along with his medical treatment, he has been applied in play therapy. During the pursuit process at the day clinic was noticed that, he had temper tantrums when he was replied with "no" and lost at games, also he threw glasses, damaged and messed up the stuff around, he had bitten his friends, and had threatened everyone about throwing himself off. He was calmed down with pause method while he had been having an anger seizure.

Furthermore, the family has been educated about the attitudes with family therapy. The mother was referred to a psychiatrist. The case was commenced to school halftime after 4 months. It was observed that the case who had had severe temper tantrums and hyperactivity started to take command and had less of temper tantrums. The methods of overcoming the temper tantrums were explained to the mother and the father. And attitude at home and at school were also consulted with teachers and parents. The mother's parental skills were improved with the consultant who has been given.

\section{Discussion}

Attention deficit hyperactivity disorder is highly comorbid with other psychiatric disorders. Each comorbid disorder modifies the overall clinical presentation and treatment response. However if there are co-morbid ADHD, conduct disorder and disruptive mood dysregulation disorder the effectiveness of stimulants on agression is lower, it may be useful to add atypical antipsychotics to the treatment and using behavioral approaches and supporting family and providing them education about the problem may be helpful [6]. Olanzapine is a thienobenzodiazepine which specifically blocks 5HT2A and D2 receptors and additionally blocks muscarinic M1, H1, 5-HT2C, 5-HT3, 5-HT6 and D4 receptors. It is used increasingly for the treatment mood disorders, schizophrenia, conduct disorder and pervasive developmental disorders at child and adolescent psychiatry clinics [7].

In our case, risperidone and aripiprazole treatment did not useful for the patient and we started to use olanzapine with OROS methylphenidate with increasing dosages because of unsatisfactory clinical response. And we practiced play therapy and behavioral approaches with family education. In the medical following process his symptoms has improvement with olanzapine and methylphenidate. Side effects like dry mouth, weith gain, increase apetite, sedation and hyperlipidemia which can cause by olanzapine, did not develop.

Olanzapine, an atypical antipsychotic agent, is used efficiently in adult schizophrenic patients. However studies about olanzapine medication in children and adolescents are significantly infrequent. In our case we used olanzapine with methylphenidate. This issue wants to get attention that these two psychopharmacologic agent is usable concomitantly ADHD and comorbidities.

\section{References}

1. American Psychiatric Association (2000) Diagnostic and Statistical Manual of Mental Disorders, 4th ed rev. Washington, DC

2. Polanczyk G, Jensen $P$ (2008) Epidemiologic considerations in attention deficit hyperactivity disorder: a review and update. Child Adolesc Psychiatr Clin N Am 17: $245-260$

3. Leibenluft E (2011) Severe mood dysregulation, irritability and diagnostic boundaries of bipolar disorder in youths. Am J Psychiatr 168: 129-142.

4. Copeland W, Angold A, Costello J (2012) Prevalance, comorbidity and correlates of DSM-5 proposed disruptive mood dysregulation disorder. Am J Psychiatry 170: 173-179. 
Citation: Vatansever Z, Ünver H, Karagöz D, Memik NÇ, Gündoğdu ÖY (2015). Attention Deficit Hyperactivity Disorder and Disruptive Mood Dysregulation Disorder Treatment with Olanzapine and Methylphenidate: A Case Report. Clin Depress 1: 105. doi:10.4172/ cdp.1000105

Page 3 of 3

5. CADDRA (2011) Canada ADHD Practice Guidelines, Third edition.

6. Semerci B, Türkbay $T$ (2012) Treatment plans and outcomes of ADHD and comorbid conditions. Bulletin of Clinical Psychopharmacology 22: 10.
7. Bozabalı Ö.G, Baykara B, Baykara A (2002) Olanzapine use in five different psychiatric disorders in children and adolescents. Bulletin of Clinical Psychopharmacology 12: 179-185.
OMICS International: Publication Benefits \& Features

\section{Unique features:}

Increased global visibility of articles through worldwide distribution and indexing

Showcasing recent research output in a timely and updated manner

- Special issues on the current trends of scientific research

Special features:

- 700 Open Access Journals

50,000 editorial team

Rapid review proces

Quality and quick editorial, review and publication processing

- Indexing at PubMed (partial), Scopus, EBSCO, Index Copernicus, Google Scholar etc.

Sharing Option: Social Networking Enabled

- Authors, Reviewers and Editors rewarded with online Scientific Credits

- Better discount for your subsequent articles

Submit your manuscript at: http://www.editorialmanager.com/medicaljournals/default.aspx
Attention Deficit Hyperactivity Disorder and Disruptive Mood Dysregulation Disorder Treatment with Olanzapine and Methylphenidate: A Case Report. Clin Depress 1: 105. 